\title{
Radiological Management of the Exiting Points of Supraorbital Region Neurovascular Bundles
}

\author{
Manejo Radiológico de los Puntos de Salida de los Haces Neurovasculares de la Región \\ Supraorbitaria
}

Mesut Sabri Tezer1; Özlem Elvan²; Ismail Yagmurhan Gilan²; Merve Türkegün³; Kaan Esen ${ }^{4}$ \& Anıl Özgür

TEZER, M. S.; ELVAN, Ö.; GILAN, I. Y.; TÜRKEGÜN, M.; ESEN, K. \& ÖZGÜR, A. Radiological management of the exiting points of supraorbital region neurovascular bundles. Int. J. Morphol., 35(4):1391-1395, 2017.

SUMMARY: A preoperative computed tomography scan is useful to determine neurovascular exit points from orbit to supraorbital region. Determining the structure of exiting points (absence or presence, if present, being in form of foramen or notch) is important to plan the surgical approach. The aim of the study was to provide the radiological data by multi-detector computed tomography for estimating exiting points of the neurovascular bundles of the supraorbital region whether through foramen or notch in living subjects related to side (right/left), sex and age. Computed tomography examinations of 214 (102 male and 112 female) adult patients, aged average $44.2 \pm 14$ years, were evaluated, retrospectively. Presence or absence, number and nature (foramen/notch) of exiting points of neurovascular bundles were noted in each side regarding sex and age groups. The distance of foramen/notch to the midline of the face was recorded. Single notch was seen on the right in 123 and in 134 on the left, single foramen was seen in 62 on the right and in 56 on the left side and double foramen was seen in 13 on the right and in 6 on the left. The absence was seen in 16 on the right and 18 on the left side. No significant difference was seen on frequency compared between the sexes and age groups. Foramen was seen in 58 sides unilaterally and in 39 sides bilaterally. Notch was unilateral in 75 sides and bilateral in 95 sides. It was shown that males had a wider distance between right side foramen and left side notch to midline. Age groups did not show a significant difference in terms of side. Absence and foramen presence made up about 30-40\% of cases. Notch was the most common form. Foramen/notch presence was statistically unaffected by the sex and age factors. In terms of surgery, preoperative assessment of orbital exit points with computed tomography is essential.

KEY WORDS: Supraorbital region; Foramen; Notch; Computed tomography; Neurovascular bundle.

\section{INTRODUCTION}

A thorough knowledge of neurovascular exit points from orbit to supraorbital region is essential in determining the technique used by the surgeon in maxillofacial, ophthalmologic and plastic surgery (Janis et al., 2008; Fallucco et al., 2012; Janis et al., 2013). Various forms of exiting points to supraorbital region have been reported in the literature. They may be foramen or notch separately or two foramina or sometimes foramen and notch together or sometimes absence of foramen and notch, proceeding in the upper wall of orbit (Andersen et al., 2001; Cheng et al., 2006; Woo et al., 2013; Tubbs et al., 2016; Filipovic et al., 2017).

With the increased supraorbital area nerve decompression surgeries in last 10 years such as migraine and endoscopic forehead lift surgeries in addition to increased Botox and local anesthetic injections, determining whether these nerves come from notch or foramen exit points is important during pre-op period (Fallucco et al.; Janis et al., 2013; Anderson et al.). A preoperative computed tomography (CT) scan might be useful in clearing this situation for the surgeon and it also helps in other ways such as choosing the surgical technique used on patient and planning the surgical approach. However, there is a limited number of studies in the literature that deal with preoperative CT scans on this subject (Turhan-Haktanır et al.; Woo et al.; Bjelakovic et al., 2016).

The aim of this study was to provide the radiological data by multi-detector CT for estimating exiting points of the neurovascular bundles of the supraorbital region (SON/F) whether through foramen or notch in living subjects related to side (right/left), sex and age.

\footnotetext{
${ }^{1}$ Otorhinolaryngology Department, Faculty of Medicine, Mersin University, Mersin, Turkey.

${ }^{2}$ Anatomy Department, Faculty of Medicine, Mersin University, Mersin, Turkey.

${ }^{3}$ Biostatistics Department, Faculty of Medicine, Mersin University, Mersin, Turkey.

${ }^{4}$ Radiology Department, Faculty of Medicine, Mersin University, Mersin, Turkey.
} 


\section{MATERIAL AND METHOD}

Study population. CT examinations of the maxillofacial region, performed between June-December 2015 in the Radiology Department of the Mersin University, were evaluated retrospectively. Consecutive 214 (102 male and 112 female) adult patients, aged between 18 and 80 years old (average $44.2 \pm 14$ years), were included in the study. Patients who had a surgery, fracture or congenital abnormality in the supraorbital region were excluded from the study. This study was approved by institutional ethics committee and performed according to the 1964 Helsinki Declaration.

CT scan technique. CT examinations were performed with a 64-row multi-detector CT scanner (Aquillon 64, Toshiba Medical, Tokyo, Japan). CT parameters for this protocol included slice thickness of $0.5 \mathrm{~mm}$, peak tube voltage of $120 \mathrm{kV}$ and tube current of $50 \mathrm{~mA}$. Reformatted three-dimensional CT images were obtained from source images on a workstation. Evaluation and measurements were performed on three-dimensional computed tomography images by two experienced radiologists in consensus.

Evaluation. Presence or absence, number and nature (foramen/notch) of exiting points of neurovascular bundles were noted in each side regarding sex and age groups. Age groups consisted of 112 cases aged between 18-45 years and 102 cases aged between $46-80$ years. The distance of foramen/notch to the midline was measured (Fig. 1) and recorded. Nasion was accepted as the midline reference point for measurements.

Statistical analysis. To summarize the data obtained, notch, foramen, sex, age groups and side categories were expressed as number (n) and percentage (\%) values. Continuous variables such as age and distance from midline were also shown with mean and standard deviation values. Student-t test was used to compare intergroup parameter differences in age and gender groups. Chi-square test was used to assess the relationship between categorical variables such as age and foramen. Significance level was set as $\mathrm{p}<0.05$ in all comparisons.

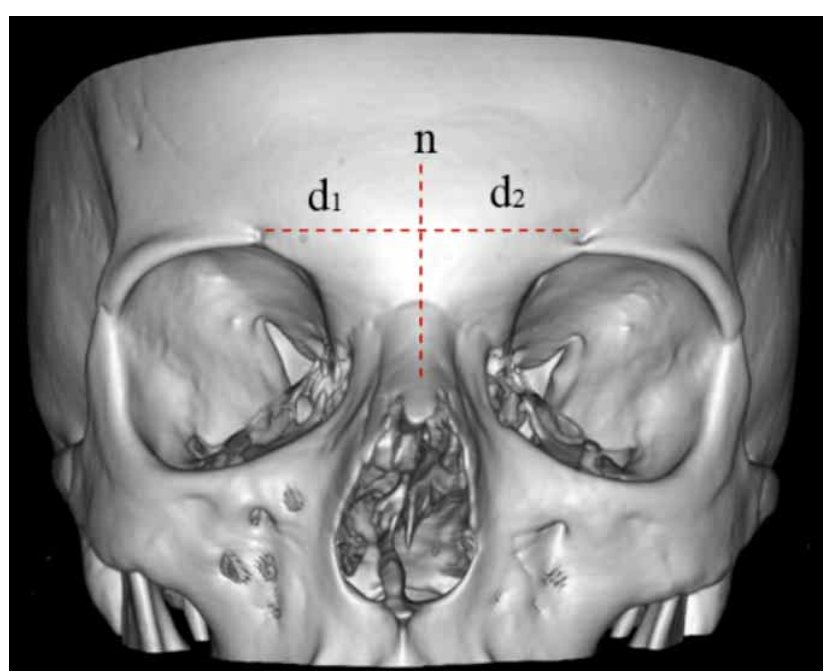

Fig. 1. The photo showing the distances from the notch to midline (d1) and from the foramen to midline (d2). n: nasion, the midline of the face.

\section{RESULTS}

The assessment of 214 cases' CT scans in terms of presence/absence status of SON/F and their percentages and spread according to sex, side and age groups was shown in Table I. The various forms of absence and presence of SON/F were demonstrated in Figure 2. If present, single notch was seen on the right in 123 and in 134 on the left, single foramen was seen in 62 on the right and in 56 on the left side and finally, double foramen was seen in 13 on the right and in 6 on the left. The absence of SON/F, i.e. the neurovascular structures exiting from their own passage to supraorbital region, was seen in 16 on the right and 18 on the left side. No significant difference was seen when presence frequency was compared between the sexes and age groups ( $p>0.05)$.

The unilateral/bilateral status of SON/F were summarized as 58 (30 female, 28 male) unilateral foramina and 39 ( 17 female, 22 male) bilateral foramina. Notch was unilateral in 75 (35 female, 40 male) and bilateral in 95 (52 female, 43 male) sides.

Table I. Numbers and percentages of foramen and notch findings regarding sex, side and age groups.

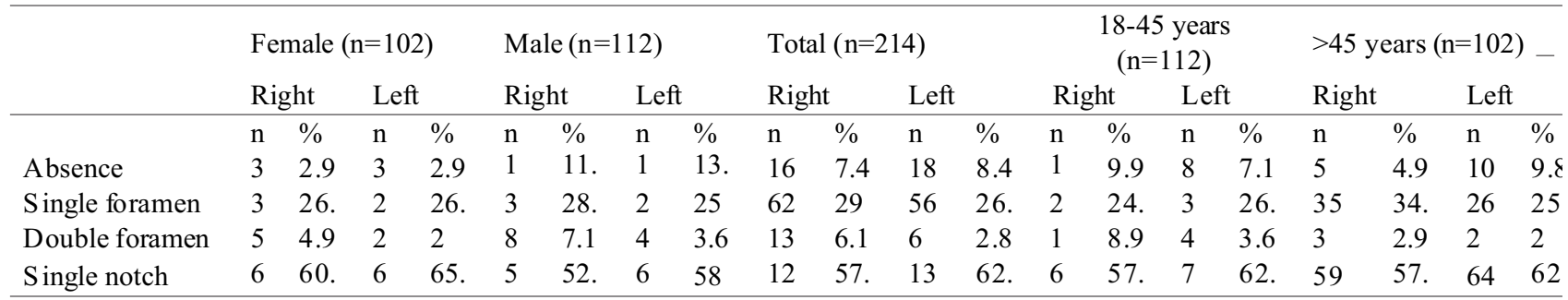




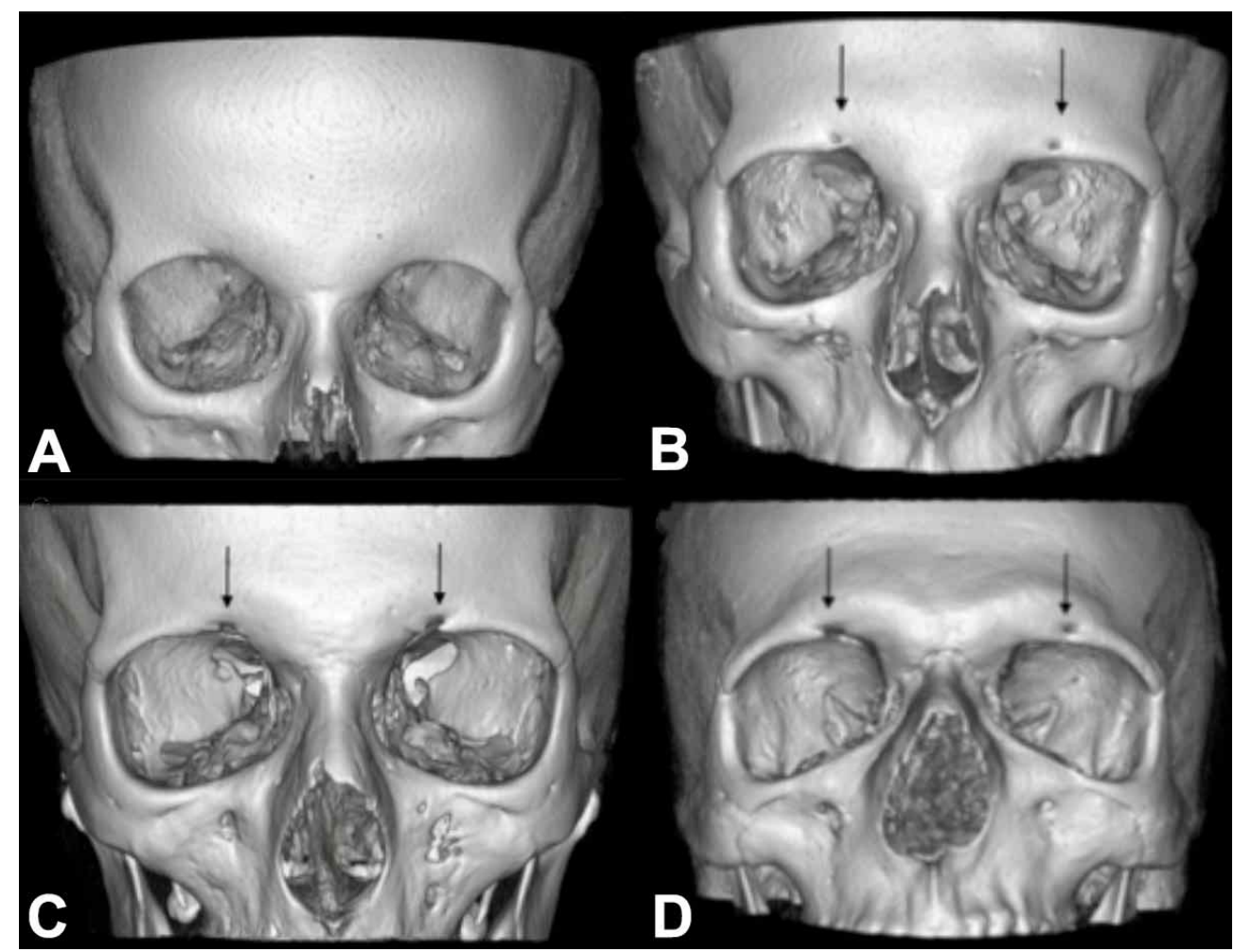

Fig. 2. The photos showing the various forms of exiting points of supraorbital neurovascular bundles: a) absence of foramen and notch on both sides, b) bilateral foramen, c) bilateral notch, d) foramen on the left and notch on the right side.

The assessment of foramen/notch midline distance according to sex and side was presented in Table II and the assessment of those according to age groups and side were shown in Table III. In comparison with females, it was shown that males had a wider distance between right side foramen and left side notch to midline $(\mathrm{p}<0.001$ and $\mathrm{p}=0.010)$. Age groups did not show a significant difference in terms of side $(\mathrm{p}>0.05)$.

Table II. Analysis of the distances from the foramen/notch to midline according to sex and side.

\begin{tabular}{lcclccc}
\hline & Right side & \multicolumn{3}{c}{ Left side } \\
& $\mathrm{n}$ & Mean \pm SD $(\mathrm{mm})$ & $\mathrm{p}$ & $\mathrm{n}$ & Mean $\pm \mathrm{SD}(\mathrm{mm})$ & $\mathrm{p}$ \\
\hline $\mathrm{d}$ 1, female & 64 & $22.6 \pm 3.7$ & 0.093 & 68 & $23.7 \pm 2.8$ & $\mathbf{0 . 0 1 0}$ \\
d1, male & 58 & $23.7 \pm 3.2$ & & 64 & $24.9 \pm 2.9$ & \\
d2, female & 30 & $24.9 \pm 3.9$ & $<0.001$ & 28 & $25.4 \pm 3.0$ & 0.155 \\
$\mathrm{~d}$ 2, male & 31 & $29.9 \pm 3.8$ & & 27 & $27.4 \pm 6.3$ & \\
\hline
\end{tabular}

$\mathrm{d} 1$ : distance between the notch and the midline, $\mathrm{d} 2$ : distance between the foramen and the midline, $\mathrm{p}$ : significance value.

Table III. Analysis of the distances from the foramen/notch to midline according to age groups and side.

\begin{tabular}{lcclccc}
\hline & \multicolumn{3}{c}{ Right side } & \multicolumn{3}{c}{ Left side } \\
& $\mathrm{n}$ & Mean $\pm \mathrm{SD}(\mathrm{mm})$ & $\mathrm{p}$ & $\mathrm{n}$ & Mean \pm SD $(\mathrm{mm})$ & $\mathrm{p}$ \\
\hline $\mathrm{d} 1,18-45$ years & 63 & $23.6 \pm 3.4$ & 0.170 & 68 & $24.3 \pm 2.8$ & 0.876 \\
$\mathrm{~d} 1,>45$ years & 59 & $22.7 \pm 3.6$ & & 64 & $24.3 \pm 3.1$ & \\
$\mathrm{~d} 2,18-45$ years & 26 & $27.6 \pm 4.5$ & 0.863 & 68 & $26.8 \pm 4.3$ & 0.546 \\
$\mathrm{~d} 2,>45$ years & 35 & $27.4 \pm 4.6$ & & 64 & $25.9 \pm 5.7$ & \\
\hline
\end{tabular}

$\mathrm{d} 1$ : distance between the notch and the midline, $\mathrm{d} 2$ : distance between the foramen and the midline, p: significance value. 


\section{DISCUSSION}

In the study, 3D images obtained by axial and coronal slices with CT were used to assess the orbital exit points of nerve structures on supraorbital region (foramen/notch or absence), their differences in terms of side, sex and age groups and their distance to midline. In the literature, although there were studies on anatomical structure of this area using dry skull (Webster et al., 1986; Gümüsburun $e t$ al., 2002), cadaver (Miller et al., 2000; Janis et al., 2008, Jeong et al., 2010; Fallucco et al.; Konofaos et al., 2013), skull and cadaver (Saylam et al., 2003) and clinical (Filipovic et al.) models, as suggested by Bjelakovic et al., we also thought that the most correct discussion method should be performed using a similar subject and methodology and therefore, we discussed our study results on previous studies that used CT scans and living samples for assessment.

The most common type was found to be single-notch ( $57.5 \%$ in the right / $62.6 \%$ in the left) and single foramen ( $29 \%$ in the right $/ 26.2 \%$ in the left) in our study. Another study by Turhan-Haktanir et al. (2008), also found similar results with single notch $(69.4 \%$ in the right $/ 68.2 \%$ in the left) and single foramen (12.4\% in the right $/ 14.5 \%$ in the left) as the most common types. Woo et al.'s study reported the presence status on the right-side notch $(39.5 \%)$ and foramen $(37 \%)$, yet it was the opposite on the left side (notch $35.4 \%$, foramen $42.3 \%$ ). The study of Bjelakovic et al., which included 105 subjects reported the most common presentation of supraorbital passage as single SON (73.33 $\%)$. In our study, we found out that foramen/notch presence was statistically unaffected by the sex and age factors in 214 cases.

The absence of foramen and notch structures, i.e. neurovascular bundle exits from own passage was found to be $7.4 \%$ on the right and $8.4 \%$ on the left side. Woo et al.'s ( $9.9 \%$ in the right $/ 11.7 \%$ in the left) and Turhan-Haktanir et al.'s (11.5\% in the right / $12.5 \%$ in the left) study results showed similarity to our own results. However, Bjelakovic et al.'s study showed a very high rate of SON/F absence with $56.19 \%$.

Males had relatively longer distances between left notch and midline $(24.9 \pm 2.9 \mathrm{~mm})$ and right-side foramenmidline (29.9 \pm 3.8$)$ compared to females in our study. TurhanHaktanir et al.'s study reported bilateral supraorbital foramina and left supraorbital notches to be more laterally located in men. Notches were significantly closer to the midline than foramina on both sides. Distances from SON/ F to midline were 32.3 and $25.8 \mathrm{~mm}$ in the right, and 29.1 and $24.6 \mathrm{~mm}$ in left sides, in male and female cases respectively. Woo et al.'s study reported the distances from the nasion to the foramen/notch were significantly greater in males. Finally, Bjelakovic et al., reported the distance of the SON/F to the facial midline was $22.52 \pm 3.2$ in males and $21.25 \pm 2.87$ in females.

Unilateral/bilateral presence rates of SON/F were more frequent in notch (17.5\% unilateral, $22.5 \%$ bilateral) and foramen was relatively rare (13.6\% unilateral / $9.1 \%$ bilateral) in the present study. Bjelakovic et al.'s study also reported more frequent unilateral $(39.01 \%)$ and bilateral (34.29\%) SON presence. SOF presence rates were reported as $2.86 \%$ unilateral and $3.81 \%$ bilateral. Moreover, no significant difference was found between the sides or the sexes.

Different from previous studies, we divided the parameters into 2 separate groups for age factor but it was statistically shown that age had no effect on those structures at all. Turhan-Haktanır et al.'s study reported a single positive correlation between the age factor and left supraorbital foramina, and no other relations with other findings.

In terms of surgery, notch can be palpated during physical examination of supraorbital region for preoperative assessment but foramen cannot be felt. In addition, in condition of absence also cannot be detected by palpation alone. In our study, absence and foramen presence made up about $30-40 \%$ of all cases. This tells us that in almost in every 3 patients, neurovascular bundle damage can be seen during sub-periosteal interventions. Especially in endoscopic face lifts and migraine surgeries, preoperative assessment of orbital exit points of that SON/F is essential for the surgeon in avoiding damage to trigeminal branch endings by increased awareness when getting close to the neurovascular bundle while working on sub-periosteal plane.

TEZER, M. S.; ELVAN, Ö.; GILAN, I. Y.; TÜRKEGÜN, M.; ESEN, K. \& ÖZGÜR, A. Manejo radiológico de los puntos de salida de los haces neurovasculares de la región supraorbitaria. Int. J. Morphol., 35(4):1391-1395, 2017.

RESUMEN: Una tomografía computarizada preoperatoria es útil para determinar los puntos de salida neurovascular en la región supraorbitaria. Para la planificación del abordaje quirúrgico es importante determinar la estructura de los puntos de salida (ausencia o presencia en forma de foramen). El objetivo de este estudio fue proporcionar los datos radiológicos mediante tomografía computarizada de detectores múltiples, para estimar los puntos de salida de los haces neurovasculares de la región supraorbitaria, ya sea a través del foramen o incisura en sujetos vivos relacionados con lado (derecho/izquierdo), sexo y edad. Se evaluaron retrospectivamente los exámenes de tomografía computarizada de 214 adultos (102 hombres y 112 mujeres), edad 44,2 \pm 14 años. Se 
observó, en cada lado, presencia o ausencia, número y naturaleza (foramen / incisura) de los puntos de salida de los haces neurovasculares en cuanto a sexo y grupos de edad. Se registró la distancia del foramen / incisura al plano mediano de la cara. Se observó un foramen a la derecha en 123 de las tomografias y en 134 a la izquierda, se observó un foramen simple en 62 a la derecha y en 56 en el lado izquierdo y se visualizó forámenes doble en 13 tomografías a la derecha y en 6 a la izquierda. Se observó ausencia en 16 casos a la derecha y 18 casos a la izquierda. No existió diferencia significativa en la frecuencia comparada entre los sexos y los grupos etarios. El foramen se detectó en 58 lados unilateralmente y en 39 lados bilateralmente. Se demostró que los hombres tenían una distancia mayor entre el foramen del lado derecho y el foramen del lado izquierdo hasta el pno mediano. No se observó una diferencia significativa en los diferentes grupos etarios en términos de lado. La ausencia y la presencia de los forámenes constituían alrededor del 30-40 \% de los casos. Los factores de sexo y edad no afectaron estadísticamente la presencia del foramen / incisura. En términos de cirugía, la evaluación preoperatoria de los puntos de salida orbitales con tomografía computarizada es esencial.

PALABRAS CLAVE: Región supraorbitaria; Foramen; Orificio; Tomografía computarizada; Haz neurovascular.

\section{REFERENCES}

Andersen, N. B.; Bovim, G. \& Sjaastad, O. The frontotemporal peripheral nerves. Topographic variations of the supraorbital, supratrochlear and auriculotemporal nerves and their possible clinical significance. Surg. Radiol. Anat., 23(2):97-104, 2001.

Bjelakovic, M. D.; Popovic, J.; Stojanov, D.; Ignjatovic, J. \& Dzopalic T. Evaluation of variability of supraorbital notches and foramina using three-dimensional computer tomography volume rendering. RAD Conf. Proc., 1:127-32, 2016.

Cheng, A. C.; Yuen, H. K.; Lucas, P. W.; Lam, D. S. \& So, K. F. Characterization and localization of the supraorbital and frontal exits of the supraorbital nerve in Chinese: an anatomic study. Ophthal. Plast. Reconstr. Surg., 22(3):209-13 2006.

Fallucco, M.; Janis, J. E. \& Hagan, R. R. The anatomical morphology of the supraorbital notch: clinical relevance to the surgical treatment of migraine headaches. Plast. Reconstr. Surg., 130(6):1227-33, 2012.

Filipovic, B.; de Ru, J. A.; van de Langenberg, R.; Borggreven, P. A.; Lackovic, Z. \& Lohuis, P. J. F. M. Decompression endoscopic surgery for frontal secondary headache attributed to supraorbital and supratrochlear nerve entrapment: a comprehensive review. Eur. Arch. Otorhinolaryngol., 274(5):2093-106, 2017.

Gümüsburun, E.; Katkici, U.; Erdil, H.; Sevim, A. \& Gulec, E. Variations of supraorbital traits. Morphologie, 86(272):19-22, 2002.

Janis, J. E., Hatef, D. A.; Hagan, R.; Schaub, T.; Liu, J. H.; Thakar, H.; Bolden, K. M.; Heller, J. B. \& Kurkjian, T. J. Anatomy of the supratrochlear nerve: implications for the surgical treatment of migraine headaches. Plast. Reconstr. Surg., 131(4):743-50, 2013.

Janis, J. E.; Ghavami, A.; Lemmon, J. A.; Leedy, J. E. \& Guyuron, B. The anatomy of the corrugator supercilii muscle: part II. Supraorbital nerve branching patterns. Plast. Reconstr. Surg., 121(1):233-40, 2008.

Jeong, S. M.; Park, K. J.; Kang, S. H.; Shin, H. W.; Kim, H.; Lee, H. K. \& Chung, Y. G. Anatomical consideration of the anterior and lateral cutaneous nerves in the scalp. J. Korean Med. Sci., 25(4):517-22, 2010.
Konofaos, P.; Soto-Miranda, M. A.; Ver Halen, J. \& Fleming, J. C. Supratrochlear and supraorbital nerves: an anatomical study and applications in the head and neck area. Ophthal. Plast. Reconstr. Surg., 29(5):403-8, 2013.

Miller, T. M.; Rudkin, G.; Honig, M.; Elahi, M. \& Adams, J. Lateral subcutaneous brow lift and interbrow muscle resection: clinical experience and anatomic studies. Plast. Reconstr. Surg., 105(3):11207, 2000.

Saylam, C.; Ozer, M. A.; Ozek, C. \& Gurler, T. Anatomical variations of the frontal and supraorbital transcranial passages. J. Craniofac. Surg., 14(1):10-2, 2003.

Tubbs, R. S.; Shoja, M. M. \& Loukas, M. Bergman's Comprehensive Encyclopedia of Human Anatomic Variation. Hoboken, WileyBlackwell, 2016.

Turhan-Haktanir, N.; Ayçiçek, A.; Haktanir, A. \& Demir, Y. Variations of supraorbital foramina in living subjects evaluated with multidetector computed tomography. Head Neck, 30(9):1211-5, 2008.

Webster, R. C.; Gaunt, J. M.; Hamdan, U. S.; Fuleihan, N. S.; Giandello, P. R. \& Smith, R. C. Supraorbital and supratrochlear notches and foramina: anatomical variations and surgical relevance. Laryngoscope, 96(3):311$5,1986$.

Woo, S. W.; Lee, H. J.; Nahm, F. S.; Lee, P. B. \& Choi, E. J . Anatomic characteristics of supraorbital foramina in korean using three-dimensional model. Korean J. Pain, 26(2):130-4, 2013.

\author{
Corresponding author: \\ Özlem Elvan \\ Mersin University Faculty of Medicine \\ Department of Anatomy \\ Ciftlikkoy Campus \\ 33343, Mersin \\ TURKEY
}

E-mail: ozlemelvan33@gmail.com

Received: 06-06-2017

Accepted: 05-07-2017 